Gunther De Vogelaer/Johanna Fanta/Greg Poarch/

Sarah Schimke/Lukas Urbanek (Münster)

\title{
Syntactic or semantic gender agreement in Dutch, German and German learner Dutch: a speeded grammaticality judgement task
}

\begin{abstract}
Dutch is currently undergoing a 'resemanticisation' of its pronominal gender, in which syntactic agreement is replaced with a system in which pronouns are chosen in accordance with the degree of individuation of the antecedent. Current accounts of resemanticisation link the process to the extent to which the three-way nominal gender distinctions are still entrenched. Using experimental data gathered with speeded grammaticality judgements from speakers of both Netherlandic and Belgian varieties of Dutch, of German, and of German learners of Dutch, we unambiguously relate the rise of semantic agreement in Dutch to an increased uncertainty with respect to grammatical gender. In addition, reaction time measurements suggest that an agreement system with a strong propensity towards grammatical agreement allows for faster processing of agreement relations than systems in which semantic agreement plays a larger role.
\end{abstract}

Zusammenfassung: Im Niederländischen findet zurzeit eine 'Resemantisierung' des pronominalen Genus statt, durch die syntaktische Kongruenz zunehmend durch ein System ersetzt wird, in dem die Wahl pronominaler Formen vom Grad der Individuierung des Antezedenten abhängt. Es wurde vermutet, dass der Prozess mit dem Grad der Verankerung (entrenchment) des Drei-Genera-Systems zusammenhängt. Anhand von Grammatikalitätsurteilen unter Zeitdruck (speeded grammaticality judgements) mit Sprechern niederländischer und belgischer Varietäten und mit Sprechern des Deutschen durchgeführt, sowie auch mit deutschen Niederländischlernern, demonstrieren wir eindeutig den Zusammenhang zwischen der Zunahme semantischer Kongruenz und einer Unsicherheit in Bezug auf das grammatische Genus. Darüber hinaus sprechen die Analysen der Reaktionszeiten dafür, dass sein stark grammatisch basiertes Genussystem eine schnellere Verarbeitung von Kongruenzbeziehungen erlaubt als ein System, in dem semantische Kongruenz eine größere Rolle spielt. 


\section{Introduction}

As is well-documented, Dutch is currently undergoing a transition by which a predominantly syntactic system of pronominal gender is resemanticised, which means replaced with a system in which semantics plays a larger role (e.g., Audring 2009a). This yields several contrasts with the neighbouring German language, which has preserved a more conservative pronominal gender system. Two of these contrasts are illustrated in (1), adopting Dutch examples from Audring (2009a: $73,98):^{1}$

(1) Semantic gender agreement in Dutch vs. German.

(1a) ...maar het meisje [...] hoe oud is ze dan? (rarely: het, it') ....aber das Mädchen [...] wie alt ist es dann? (also: sie 'she') ...but the girl [...] how old is she/it then?

'About the girl [...] how old is she really?'

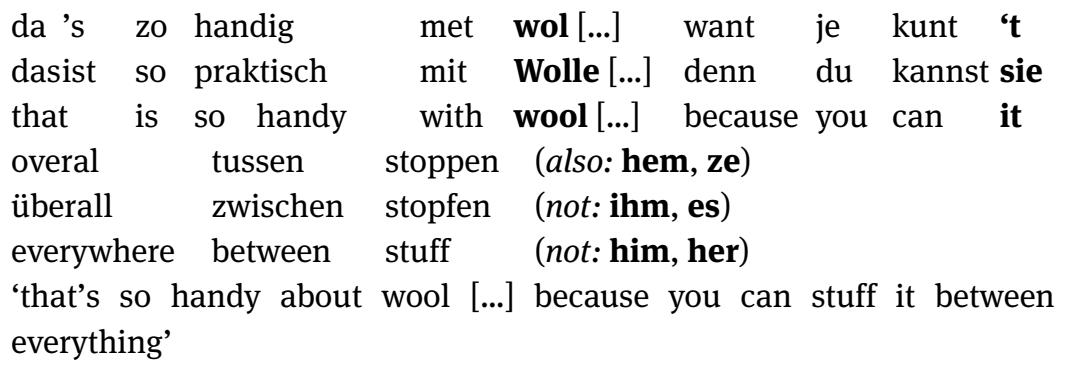

The example in (1a) concerns the noun meisje/Mädchen 'girl', which refers to an animate entity ranking high on the so-called Individuation Hierarchy (Sasse 1993; Siemund 2008), as do all entities that carry biological gender. In this case, there is a conflict between biological gender (female) and the noun's neuter gender, which yields the possibility to use feminine pronouns like Dutch $z e$ or German sie 'she', rather than the neuter pronoun (Dutch het, German es 'it'). In this and comparable cases in the animate domain, Dutch more commonly applies the so-called natural gender rule than German (Kraaikamp 2017: 63-73). Example (1b) concerns the low end of the Individuation Hierarchy, in that a mass noun, viz. wol/

1 We would like to thank Marc Brysbaert at Ghent University and Josje Verhagen at Utrecht University for assistance in recruiting test persons and for letting us use psycholinguistic testing infrastructure. Thanks are also due to Holger Hopp for sharing the experimental task with us and to two anonymous reviewers for their constructive criticism and comments. 
Wolle 'wool', refers to an unspecific quantity of a substance. In such conditions, Dutch shows an increasing tendency to use the neuter pronoun (het), even if the noun involved has common gender (or is feminine in three-gender varieties of Dutch). Whereas the same phenomenon exists in German as well (see Audring 2009a: 193 for examples), it is by no means as widespread as in Dutch (Kraaikamp 2017: 74). (1b) also hints at a further difference between Dutch and German: in line with its tryadic gender system, German uses masculine and feminine pronouns to refer to masculine and feminine nouns, respectively. Most varieties of Dutch, however, have collapsed masculine and feminine gender into common gender (or de-nouns), and use masculine pronouns for syntactic agreement with this category. Example (1b) is a case in point: the pronoun hem 'him' is much more commonly used than ze 'her' in Dutch, even though the noun wol is, as a cognate of German Wolle 'wool', historically feminine.

This article zooms in on the changes illustrated in (1b), and investigates the psycholinguistic status of the variants involved. Current research on resemanticisation has primarily dealt with data from language usage and has proposed a number of explanations for the phenomenon. While these are, essentially, psycholinguistic in nature, there have been few attempts to tap into speakers' knowledge of their gender system more directly. Section 2 provides an overview of research carried out by means of usage data and formulates several hypotheses regarding the psycholinguistics of pronominal gender in Dutch. Section 3 then describes the method adopted in our own investigation, which is geared at providing more insight into the status of syntactic vis-à-vis semantic gender agreement by means of two speeded grammaticality judgement tasks, targeting the relation between syntactic and semantic agreement (Experiment 1), and the masculine-feminine distinction (Experiment 2), respectively. Section 4 describes the results, and in section 5 some conclusions are drawn.

\section{Production data on Dutch and German pronominal gender: Overview}

As said above, this article zooms in on the resemanticisation of pronominal gender in the inanimate domain, which was illustrated by means of (1b). The term 'resemanticisation', coined by Wurzel (1986), considers that all gender systems are assumed to have a semantic core (Corbett 1991: 63), including the common ancestor languages of Dutch and German. Audring (2006: 108) therefore evaluates the change observed in Dutch as a result of semantic agreement merely becoming more visible (again), rather than as an original development 
(cf., among others, Schwink 2004 and Jobin 2011 on Proto-Germanic, Matasovič 2004 and Luraghi 2011 on Proto-Indo-European, and Kraaikamp 2017 for further evidence on Dutch).

Whether semantic or syntactic agreement is used in a given situation, depends on many factors, some of which are inherent to the referent of the pronoun (e.g., whether it is highly individuated or not) or the noun involved (e.g., usage frequency, cf. De Vos/De Vogelaer 2011), whereas others relate to the syntactic or discourse context in which the pronoun or its antecedent are used. Among the factors that have been proposed for Dutch are the pronoun's grammatical case, the distance between antecedent and pronoun (Audring 2009a), the antecedent's definiteness and its grammatical function, the verb of both the antecedent and the pronoun sentence (De Vos 2014), anaphoric vs. deictic reference, and the presence of a gender marker in the antecedent NP (Kraaikamp 2017). In addition, in a changein-progress like resemanticisation in Dutch, sociolinguistic factors like speakers' gender, age and social background may play a role as well (see Audring 2009a: 168f. and De Vos 2014: 166-186 for discussion). Not all of these parameters can be included in a comparative study, however, even more so because many of them interact and their effects should therefore be studied in a multivariate analysis of a larger dataset than the one used below. For the present investigation, most of them will be kept constant.

As for the most important factor, viz. the semantics of the pronoun's referent, the investigation needs to take into account variation in the way semantic agreement is implemented. While the use of neuter pronouns in reference to non-neuter mass nouns has been documented throughout (and beyond) the West Germanic languages, there appears to be variation with respect to inanimates ranking more highly on the Individuation Hierarchy: for instance, Audring's (2009a) analysis of the Spoken Dutch Corpus zooms in on the geographical centre of the Dutch language area (Holland or the broader Randstad area), and reveals a tendency to generalize masculine pronouns for highly specific and/or delineated referents, typically count nouns, even if these have neuter gender (e.g., a count noun like het boek 'the book' would increasingly be referred to with hij 'he' or hem 'him'). Similar examples from peripheral areas in the Netherlands and from Belgium are lacking, however; it appears as if in these areas neuter het 'it' is expanding its use in referring to all inanimates, including count nouns (e.g., a count noun like de doos 'the box' would be referred to with het 'it', albeit less frequently than mass nouns). In a schema such as (2), the variation is described in terms of different cut-off points between the usage ranges of different pronouns: whereas Holland distinguishes between highly and lowly individuated inanimates for pronominal reference, the semantic system elsewhere treats inanimates as a single category that triggers, from a semantic point of view, the use of het 'it'. 
(2) Semantic gender in Dutch: different cut-off points.

\begin{tabular}{|c|c|c|c|c|c|c|}
\hline & Human & $\begin{array}{l}\text { Other } \\
\text { animate }\end{array}$ & $\begin{array}{l}>\begin{array}{l}\text { Bounded } \\
\text { object/ }\end{array} \\
\text { Abstract }\end{array}$ & $\begin{array}{l}>\text { Specific } \\
\text { mass }\end{array}$ & & $\begin{array}{l}\text { Unspecific mass, } \\
\text { Unbounded } \\
\text { abstract }\end{array}$ \\
\hline $\begin{array}{l}\text { Holland (cf. Audring } \\
\text { 2006: 103): }\end{array}$ & & $\mathrm{HIJ} / \mathrm{ZIJ}$ & HIJ & & & HET \\
\hline $\begin{array}{l}\text { Belgium, periphery of } \\
\text { the Netherlands } \\
\text { (cf. Klom/De Vogelaer } \\
\text { 2017): }\end{array}$ & & HIJ/ZIJ & & & HET & \\
\hline
\end{tabular}

Similar variation is known from English, where the standard variety has generalized it for inanimates and animates with unknown (or backgrounded) biological gender, much like the varieties of Dutch spoken in the periphery of the language area are doing. Several non-standard varieties have alternative systems at their disposal, however, which resemble the Hollandic system, in which he/him are used in combination with highly individuated inanimates (see cask in example 3a from Siemund 2008). The few data that are available for German, which has only marginal proportions of semantic gender, indicate that it behaves like peripheral varieties of Dutch: a few exceptions notwithstanding, deviations from lexical gender are explained either as effects of the natural gender rule, or as neuter pronouns used in line with a masculine/feminine referent's low individuation (Kraaikamp 2017: 68-73; cf. example 3b).

(3) Examples of semantic gender in English and German.

(3a) Thick there cask 'ont hold, tidn no good to put it [the liquid] in he [the cask] (Southwest of England; Siemund 2008: 46)

(3b) Wir müssen zuerst $E_{\text {rde }}$ entsorgen. Ich hoffe, dass es ${ }_{\text {neut }}$ we must first earth dispose.of. I hope that it mit einem mal transportiert werden kann. (Kraaikamp 2017: 70) with one time transported become can

'First we must dispose of the earth. I hope it can be transported in one time.'

Apart from different implementations of semantic gender in the inanimate domain, Dutch also shows extensive variation with respect to the degree of semantic gender that is observed. In general, Netherlandic Dutch has developed a stronger prefer- 
ence for semantic gender, whereas Belgian varieties show higher proportions of syntactic agreement (compare Audring 2009a and De Vos 2014). This is correlated to the fact that Belgian varieties have preserved richer gender marking in the noun phrase: in the inflectional paradigm of articles and/or adjectives, many Belgian varieties still distinguish between masculine and feminine gender (usually by attaching an -en-suffix to articles and adjectives preceding masculine nouns) and therefore qualify as three-gender varieties of Dutch. In contrast, the two-gender varieties spoken in the northern half of the language area have merely preserved the common-neuter distinction (see Van Ginneken 1934f. and 1936f. for maps). While suffixes marking the masculine-feminine distinction in the adnominal domain are associated with non-standard varieties, the distinction between twoand three-gender varieties is also relevant for Standard Dutch, in that it is reflected in pronominal reference: the south, most notably Belgian Dutch, (also) uses ze to refer to feminine $d e$-words, whereas the north has generalised masculine hij/hem 'he/him' for all $d e$-words. The three-gender area appears to be eroding: Hoppenbrouwers (1983) documents the loss of the masculine-feminine distinction in both pronominal and adnominal gender in a North-Brabantic variety of Dutch, and relates it to processes of dialect levelling and loss. De Vogelaer/De Sutter (2011) show that, within the three-gender area, the varieties with the richest adnominal system are also the most resilient ones with respect to resemanticisation. ${ }^{2}$

The tight link between richness of the adnominal paradigm and degree of resemanticisation is observed in other languages: both in Germanic and in Romance, resemanticisation appears to have affected two-gender systems more systematically than three-gender systems (Siemund 2008; Fernández-Ordóñez 2009; Audring 2009a: 198f.). In addition, Audring (2009a: 211, 2009b) reveals a typological link between purely pronominal gender marking and semantic gender, with distinctions relating to individuation (count/mass, animate/inanimate) ranking among the most common semantic parameters steering pronominal agreement. This suggests a causal link between the (partial) collapse of the inflectional system in the adnominal domain, and resemanticisation, in that syntactic systems of pronominal agreement can only be upheld if they are 'supported' by

2 The state border between Belgium and the Netherlands does not coincide at all with the isoglos separating the two- and three-gender area. Since the latter area stretches out until deep in the Netherlands, it is common in the dialectological literature on the topic to distinguish northern and southern varieties rather than Netherlandic and Belgian ones. Since standardisation processes have exerted stronger pressure on the three-gender varieties in the Netherlands, the two- and three-gender systems have become associated with Netherlandic and Belgian Dutch, respectively, and we conveniently describe the contrasts as differences between national varieties of Dutch (see Klom/De Vogelaer 2017 for elaboration, however). 
an adnominal system. Ultimately, resemanticisation would then be explained psycholinguistically by means of scenarios that can be called 'learnability' or 'entrenchment accounts': in a language with covert gender like Dutch, nouns' gender can only be learned through the behaviour of associated words. To be successfully acquired, then, gender must be properly entrenched in the input. Audring's findings indicate that this is only the case in languages with sufficiently rich and consistent gender marking in the adnominal system. ${ }^{3}$ If gender marking no longer allows learners to acquire the system, language users increasingly have to resort to semantic rules in pronominal reference, which, in the long run, could lead to language change.

There are different hypotheses on the precise features of the adnominal system that ensure grammatical gender to be properly entrenched. Audring's (2009a: 172) 'mismatch hypothesis' points out that the contrast between two genders in the adnominal domain and three pronominal genders may be problematic. Since resemanticisation is also observed in three-gender varieties of Dutch, however, incomplete patterns of syncretism may suffice to trigger the change. In this vein, De Vogelaer/De Sutter (2011: 195) discuss the role of $n$-deletion in paradigms in which $-n$ is used as the main marker for masculine gender, and also illustrate the role of the masculine indefinite article $n e(n)$, which apparently causes EastFlemish varieties of Dutch to lag behind in resemanticisation in comparison to West-Flemish, which has an invariable indefinite article. The loss of gender marking on the indefinite article is also mentioned by Kraaikamp (2017: 126f.), who points out that gender marking has been lost in more agreement targets in Dutch, such as most possessives, and attributive articles in definite NPs. Apart from the distinctiveness of agreement suffixes and the number of agreement targets, the gender assignment system may also play a role: Dutch gender is assumed to be by and large arbitrary (Audring/Booij 2009), which contrasts with languages in which lexical gender is motivated on formal or semantic grounds (e.g., German, in which nouns on schwa tend to be feminine, or long objects tend to be masculine; see Köpcke/Zubin 1983), and/or even morphologically marked on the noun (e.g., Italian has masculines on - $o$ and feminines on - $a$ ).

3 One can speculate about the reasons why pronominal agreement would not fulfill such an entrenchment requirement. A possible factor would be the, on average, larger distance between pronouns and their controllers (the noun), and their, in typological perspective, stronger preference for semantic agreement. Both blur the agreement relationship between pronouns and their antecedents. In addition, languages like Dutch use surprisingly few pronouns to refer to inanimates. The latter point can be illustrated with data from De Vos (2014), who finds a mere 3463 references to inanimates in the entire Flemish part of the Spoken Dutch Corpus, which consists of about 3 million words. 
Numerous acquisition studies illustrate that gender, as entrenchment accounts would predict, is indeed much harder to acquire in Dutch than in German. Whereas mistakes in the adnominal domain are rare even in young German-speaking children (Mills 1986; Szagun et al. 2007), these abound in Dutch (Van der Velde 2003: 128, 138; Cornips/Hulk 2006; Blom/Polišenská/Weerman 2008). In the pronominal domain, Dutch-speaking children conceive of pronominal gender predominantly as a semantic system; syntactic gender is acquired later (De Houwer 1987; De Vogelaer 2010; De Vos/De Vogelaer 2011). Children growing up in the three-gender area apply the grammatical gender system more consistently, both in the adnominal and pronominal domain (see, respectively, Cornips/Hulk 2006 and De Vogelaer 2010). Not surprisingly, the grammatical gender system poses an even bigger challenge for non-native learners of Dutch (see Cornips/Hulk 2006; Blom/Polišenská/Weerman 2008, and Loerts 2012 for adnominal gender, and van Emmerik et al. 2009 for pronouns). German learners of Dutch are an exception to this, however. Since these have been found to use a "direct gender translation strategy" (Sabourin/Stowe/De Haan 2006: 24), and given extensive correspondences between German and Dutch gender both on the systemic and the lexical level, syntactic agreement should be acquired with relative ease. Since they have also been found to exploit knowledge of their native language (L1) even in circumstances where correlations between the L1 and the L2 are missing (Lemhöfer/ Schriefers/Hanique 2010: 157), an investigation into German-speaking learners of Dutch may reveal whether some of the recent findings regarding the Dutch gender system transfer to German as well.

The results of acquisition studies are, broadly speaking, in line with the predictions yielded by entrenchment accounts of resemanticisation. Yet these acquisition data, as other production data, do not provide any direct insight into the grammatical knowledge of the language users involved. Even if resemanticisation is observed, for instance, it cannot be determined to what extent this is caused by a weakened entrenchment of lexical gender or whether this relates to the acceptability of syntactic agreement being affected. Changing usage preferences may also be explained by conscious attempts to adopt a system increasingly favouring semantic agreement, especially since resemanticisation appears to be most strongly observed in Holland, which is the normative centre of the Dutch language area. Therefore, this article aims at tapping more directly into the Dutch and German gender system, using data from a psycholinguistic experiment carried out on German, Netherlandic Dutch, and Belgian Dutch speakers, and on German learners of Dutch. The following hypotheses will be explored:

- Syntactic agreement is expected to be the dominant agreement mode in German, and be more stable in Belgian Dutch than in Dutch from the Nether- 
lands. German learners of Dutch are expected to rely on lexical gender, which means use syntactic agreement, more than on semantics.

- German still shows a stable three-gender system, whereas feminine gender is vulnerable in Dutch, and even no longer found in Netherlandic varieties.

- Semantic agreement is more strongly observed in Netherlandic Dutch than in Belgian Dutch. German shows a non-negligible amount of semantic agreement, too, and in particular allows combinations of lowly individuated non-neuter nouns and neuter pronouns.

\section{Method}

\subsection{Participants}

The method adopted for this psycholinguistic investigation is the so-called speeded grammaticality judgement task: participants are asked to evaluate the grammaticality of a number of test sentences as fast as possible. Both the participants' evaluations and their reaction times provide insight into their underlying grammatical knowledge.

[T]he speeded presentation of the stimuli and the rapidly enforced judgement are taken to reflect processing strategies because the pace of the task (a) forces the parser to adopt its preferred parsing route and (b) does not allow for enough time to complete reanalysis [...]. The rationale underlying the speeded judgement paradigm is that, under time pressure, sentences dispreferred by the parser elicit lower accuracy scores and higher reaction times than comparable control sentences. (Hopp 2007: 238)

Speeded grammaticality judgements allow investigating separately the role of semantic vis-à-vis syntactic agreement in sentence processing, because all conceivable combinations of noun gender and particular pronouns can be tested, including infrequent and ungrammatical patterns. As such they provide information that remains invisible in an analysis of production data, which primarily yield insight into which variants are preferred (cf. Tremblay 2005: 159). In order to test the hypotheses formulated above, two experiments were developed, focusing on the alternation between syntactic and semantic agreement for masculine and neuter antecedent NPs, and on the masculine-feminine distinction, respectively. Both experiments were carried out in four groups of participants, viz. L1 speakers of a Netherlandic variety of Dutch (recruited in Utrecht; $n=23$ ), L1 speakers of a Belgian variety of Dutch (recruited in Ghent; $n=25$ ), German learners of Dutch (recruited in Münster; n=28), and L1 speakers of German (recruited in Münster 
and Vienna; $n=20)$. All participants were university students in the age range 20-45 years.

\subsection{Material}

The investigation focused on mass nouns, since only lowly individuated nouns behave uniformly with respect to resemanticisation (see above). To address our hypotheses, nouns of a given lexical gender were combined with certain pronouns, with Experiment 1 testing the effect of semantic vis-à-vis syntactic agreement, and Experiment 2 testing the resilience of feminine gender. Of nine possible gender-pronoun combinations, two were excluded, because they do not occur in production data (neuter noun - feminine pronoun), or because their behaviour can be predicted on the basis of other categories (the combination feminine noun - neuter pronoun is expected to behave similarly as masculine noun - neuter pronoun). The experimental items were selected on the basis of both the German and the Dutch gender system, as described in the Duden (2015 edition) and the Grote Van Dale (2015 edition), respectively. For Dutch gender, the opposition between masculine and feminine $d e$-words was considered, since the investigation also targets three-gender varieties of Dutch. Some investigations on Dutch gender have yielded frequency effects (e.g., De Vos/De Vogelaer 2011; De Vogelaer 2012), so usage frequency was included in the analysis, too. Whereas the nouns were not selected to vary systematically in frequency, and only cover a limited frequency range, it was investigated whether frequency affected the acceptance of the conditions in both experiments, by adding the frequency of the nouns according to the subtlex-NL corpus (Keuleers/Brysbaert/New 2010) to all models as a continuous predictor variable.

All nouns are cognates in Dutch and German, with identical gender in both languages (however, with one exception) ${ }^{4}$; hence, the Dutch and German versions of the test consisted of maximally equivalent test sentences. Both experiments consisted of 75 sentences each, which means 36 experimental items and 39 fillers (15 grammatical and 24 ungrammatical ones), which were included to avoid routine answering strategies (cf. Hopp 2007: 240). The order of the test items was

4 The one exception, viz. stof/Stoff ('fabric'), has feminine gender in Dutch and masculine in German, which in fact allows detecting a "direct gender translation strategy" (Sabourin/Stowe/De Haan 2006: 24) on the part of the German learners of Dutch. Indeed they do not use any feminine pronouns in the production task and consistently rate feminine pronouns as ungrammatical (see Urbanek et al. 2017: 162-164 for further discussion). 
randomised, with experimental and filler sentences alternating in an unpredictable manner.

The test sentences from Experiment 1 represent four conditions, with 18 masculine nouns and 18 neuter nouns, of which half are combined with a masculine subject pronoun (Dutch hij, German er), and the other half with a neuter pronoun (Dutch het, German es). In Experiment 2, four conditions were tested as well: half of 18 masculine and 18 feminine nouns combine with masculine subject pronouns (Dutch hij, German er), and the other half with a feminine pronoun (Dutch ze, German sie). Since the masculine test items were used in both Experiment 1 and 2, the total number of nouns in the test equals 54. To ensure maximal comparability across the experimental conditions, two versions of both experiments were designed, in which test items were combined with a different pronoun, yielding A and B versions of both experiments. Table 1 presents a few examples of test sentences from both versions (of the Dutch test).

Table 1: Examples of test sentences in Dutch

List A:

List B:

Experiment 1

De suiker $_{\text {masc. }}$ is gevaarlijk, want het neut. $_{\text {is oud. De suiker }}$ masc. is gevaarlijk, want hij $_{\text {masc. }}$ is oud. The sugar is dangerous because it is old. The sugar is dangerous because he is old.

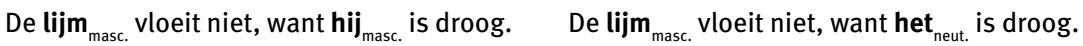
The glue does not flow because he is dry. The glue does not flow because it is dry. ${\text { Het } \text { gras }_{\text {neut. }} \text { brandt niet, want het }}_{\text {neut. }}$ is sappig. Het gras neut. $_{\text {brandt niet, want }} \mathbf{h i j}_{\text {masc. }}$ is sappig. The grass does not burn because it is juicy. The grass does not burn because he is juicy.

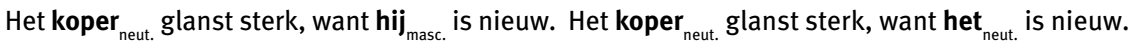
The copper shines brightly because he is new. The copper shines brightly because it is new.

Experiment 2:

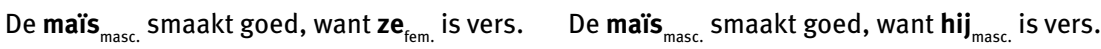
The maize tastes well because she is fresh. The maize tastes well because he is fresh.

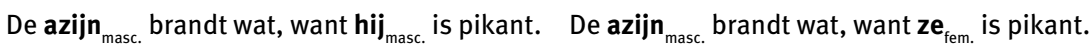
The vinager burns a bit because he is spicy. The vinager burns a bit because she is spicy. De zeep $_{\text {fem. }}$ kost veel, want hij masc. $_{\text {is mild. } \quad \text { De zeep fem. }}$ kost veel, want ze fem. $_{\text {is mild. }}$ is. The soap costs much because he is mild. The soap costs much because she is mild.

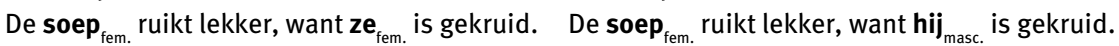
The soup smells nice because she is seasoned. The soup smells nice because he is seasoned.

Since the likelihood of semantic agreement in Dutch is influenced by the syntax of the antecedent NP (e.g., definiteness) as well as by the predicate of both the antecedent clause and the pronoun clause (De Vos 2013, 2014), test sentences uni- 
formly contained antecedents used in a definite NP, in a clause with an activity verb $(n=32)$, a state verb $(n=32)$, or a combination of the copula $z$ ijn/sein 'to be' and an adjective $(n=8)$. The activity and state verbs in the antecedent sentences were followed by an adverb to keep the length of the sentence equivalent. The pronoun sentence was invariably introduced by the complementizer want/denn 'because', followed by the anaphoric pronoun, the copula zijn/sein 'to be' and an adjective. All lexical items consisted of maximally three syllables.

The ungrammatical fillers contained ungrammatical plurals, ungrammatical word orders, and false verb agreements. The grammatical filler sentences were modelled after the ungrammatical ones, but did not contain any ungrammaticalities.

\subsection{Procedure}

The two experiments were designed with the software package E-Prime (Schneider/ Eschman/Zuccolotto 2012). Sentences were shown in a word-by-word fashion on a computer. Each word was shown for 250 milliseconds (ms) plus $18 \mathrm{~ms}$ per letter, before a blue screen appeared and participants were asked to evaluate the sentences' grammaticality by means of a red (ungrammatical, rightmost button) and green button (grammatical, leftmost button). The maximal time allotted for the judgements was 4 seconds. In between both experiments, participants were administered a language background questionnaire (LSBQ, Anderson et al. 2017). After the second experiment they were asked to take part in a production test, in which they had to fill out pronouns in a questionnaire containing the same test sentences as the experiments. For the analysis carried out in this contribution, the language background questionnaire was merely used to detect participants with special backgrounds (e.g., bilingual education, non-native speakers, ...); results of the production test are not analysed here (but see Urbanek et al. 2017). The entire procedure took about 30 minutes per participant.

\section{Results}

\subsection{Experiment 1: syntactic vs. semantic gender}

Experiment 1 was designed to evaluate the status of syntactic and semantic agreement in the language varieties involved. Nouns of masculine and neuter gender were combined with either a masculine or a neuter pronoun, constituting 
four different conditions. Given the fact that all nouns involved were mass nouns, combinations with masculine nouns present unambiguous examples of syntactic agreement (masculine > hij/er 'he') or semantic agreement (masculine > het/es 'it'). Combinations of neuter nouns with masculine pronouns are neither motivated by syntactic, nor by semantic agreement; for combinations of neuter nouns with neuter pronouns, syntactic and semantic agreement match. While a detailed analysis of the data is carried out below using mixed effect models, a first glance at the overall results in Figure 1 already shows that, in general, combinations with neuter nouns trigger the clearest evaluations: the combination of neuter nouns with neuter pronouns yields the highest acceptance ratios, and the combination of neuter nouns with masculine pronouns is most strongly, but not across the board, judged ungrammatical. This corresponds to the fact that syntactic and semantic agreement have matching outcomes for neuter nouns. The results with masculine nouns, for which syntactic and semantic agreement conflict, tend to be more mixed. A slight preference for masculine pronouns is observed in the German L1 speakers and the German learners of Dutch, and for neuter pronouns in both Netherlandic and Belgian L1 speakers of Dutch.

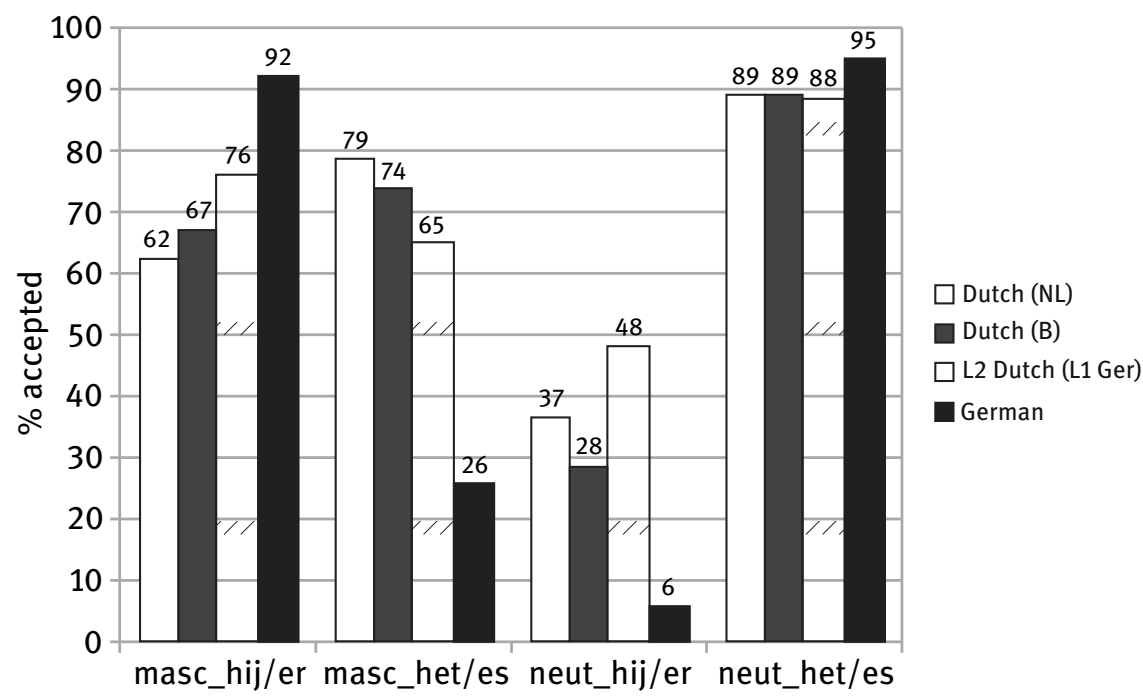

Fig. 1: Grammaticality judgements on syntactic vs. semantic agreement

To analyse the differences between the tested groups, we used logistic mixed effects models with 'choice' (grammatical, ungrammatical) as dependent variable and random intercepts for items and participants. As a complex model that 
included the three-way interaction between (participant) 'Group', 'Pronoun' and 'Antecedent' (gender: masc/neut) did not converge, and as our research questions do not concern potential main effects of 'Group' as far as the judgements are concerned, we conducted separate subset models, testing for effects of Pronoun, Antecedent (masc/neut), and their interaction in each of the four groups. A further parameter, 'Frequency', was not included in the final model, since an initial analysis including this factor showed that neither a main effect of Frequency nor an interaction with another factor was observed in the three varieties of Dutch in the investigation. The results of these analyses are summarized in Table 2, which includes $z$-scores as a measure for effect size, and p-values for significance.

Table 2: Experiment 1: Mixed effect modelling of factors ‘Antecedent', ‘Pronoun' and their interaction, for four participant groups

\begin{tabular}{|c|c|c|c|}
\hline & Antecedent (masc/neut) & Pronoun & Antecedent * Pronoun \\
\hline Dutch (NL) & n.s. & $\begin{array}{l}z=10.40 \\
p<.001 * \star \star\end{array}$ & $\begin{array}{l}z=-5.68 \\
p<.001 * \star \star\end{array}$ \\
\hline Dutch (B) & $\begin{array}{l}z=1.90 \\
p=.05\end{array}$ & $\begin{array}{l}z=10.82 \\
p<.001 * \star \star\end{array}$ & $\begin{array}{l}z=-8.94 \\
p<.001\end{array}$ \\
\hline $\begin{array}{l}\text { L2 Dutch } \\
\text { (L1 German) }\end{array}$ & n.s. & 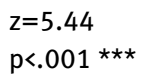 & 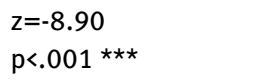 \\
\hline German & $\begin{array}{l}z=1.90 \\
p=.05\end{array}$ & $\begin{array}{l}z=3.90 \\
p<.001 * * *\end{array}$ & $\begin{array}{l}z=-14.45 \\
p<.001 * \star \star\end{array}$ \\
\hline
\end{tabular}

These results show a significant interaction between Pronoun and Antecedent (masc/neut) in all groups, which was also visible in Figure 1 through the fact that the two pronouns do not have the same acceptability depending on the antecedent. This is the expected effect of syntactic agreement. More interestingly, the data also reveal a main effect of pronoun in all groups, because the pronoun het/es 'it' is overall more acceptable than the pronoun hij/er 'he'. This is most strongly the case in the L1 varieties of Dutch, where it is in line with the expected semantic agreement pattern, but the effect is also observed in German learner Dutch and L1 German. Finally, the marginal effect of Antecedent (masc/neut) in the Belgian Dutch and the German group is due to the overall less positive judgements for neuter antecedents. This effect is carried by the low acceptability of the combination of a neuter antecedent and the pronoun hij/er in these two groups.

Examining some of the patterns in more detail, the combinations of neuter nouns with masculine pronouns (hij/er 'he'), first, yielded the least approval, 
which is in line with the fact that they are neither the outcome of syntactic, nor of semantic agreement. Still, much more instances of this type are judged grammatical in varieties of Dutch than of the ungrammatical fillers. This holds both for L1 speakers (where ungrammatical fillers on average get some 10\% positive evaluations vs. $28 \%$ (B) or 37\% (NL) of neut_hij/er combinations) and for German L2 learners of Dutch (with $30 \%$ of ungrammatical fillers approved of vs. $48 \%$ of neut_hij/er combinations). Hence, in addition to resemanticisation, the answers of the Dutch L1 speakers, and likely also those of German L2 learners, can be interpreted as indications of uncertainty regarding gender agreement, which cannot be explained on semantic grounds. This uncertainty is not found in L1 German. Second, the combinations with masculine nouns are particularly insightful to determine the alternation between syntactic and semantic agreement. In both Netherlandic and Belgian Dutch, acceptance of semantic agreement (around $75 \%$ ) is higher than of syntactic agreement (around 60\%). Although Belgian Dutch tends towards syntactic agreement slightly more than Netherlandic Dutch, the difference between both varieties is smaller than could have been expected from the literature. In contrast, in L1 German syntactic agreement (masc_hij/er) is by far the preferred option, despite a non-negligible acceptance of semantic agreement (masc_het/es) of 26\%. The German L2 learners, finally, show a preference for syntactic agreement, which can be considered a transfer effect. They also show a high acceptance of semantically motivated neuter pronouns for masculine mass nouns, however, which could, in principle, both be transferred from their L1 or learned. Even though the $65 \%$ proportion of semantic agreement exceeds the proportion of 26\% found in the L1 German group, Urbanek et al. (2017) argue that semantic agreement in German L2 Dutch is transferred, since the pattern does not become stronger in more proficient learners.

Regarding the participants' reaction times (RT), the general expectation is that a low acceptance correlates with slower RTs (Hopp 2007: 238). However, the availability of both syntactic and semantic agreement may already impact RTs, in that computing the outcome in such a complex system may require additional processing effort. It can be hypothesized that processing will be faster when the grammatical principles involved yield the same outcome than in cases of conflict. In Experiment 1, syntactic and semantic agreement yield matching outcomes for neuter nouns (with het/es 'it' being grammatical and hij/er 'he' ungrammatical) and mismatching outcomes for masculine gender nouns (with syntactic agreement yielding hij/er 'he' and semantic agreement het/es 'it', given that all nouns involved are mass nouns). The results are displayed in Figure 2, which orders data per investigated variety to highlight intra-group differences. In contrast with Figure 1, a first glance reveals few tendencies holding across the board, apart from the fact that both in native and non-native Dutch, the neut_het/es-condition yields the fastest RTs. 


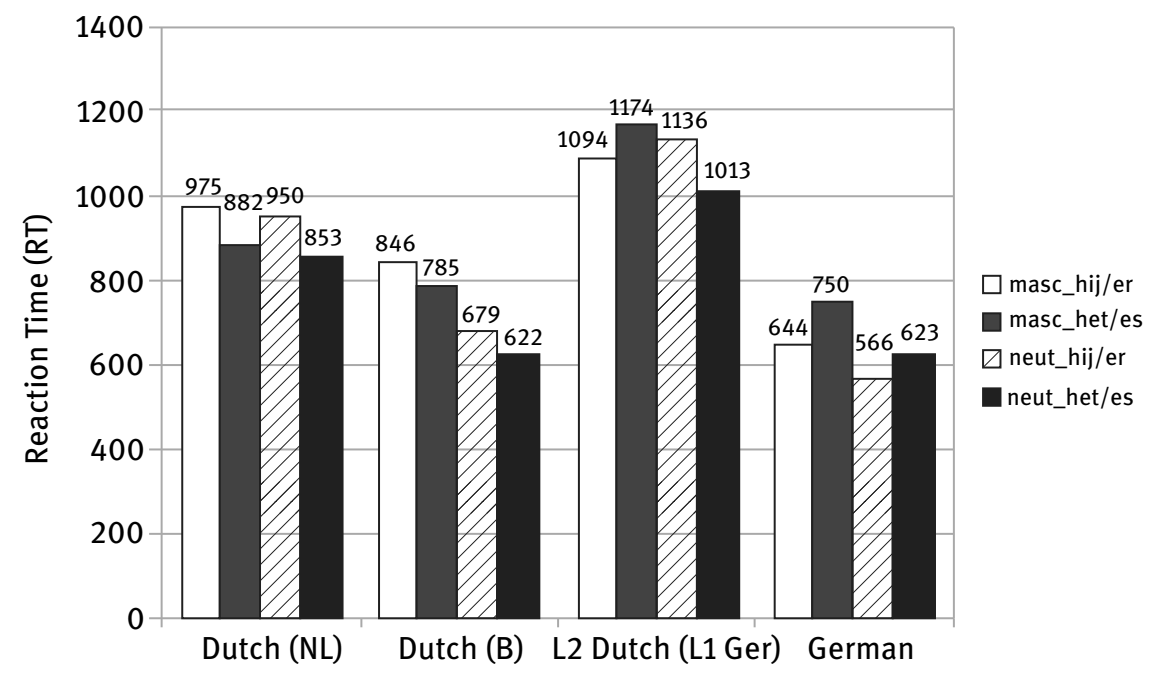

Fig. 2: Reaction times (milliseconds) on syntactic vs. semantic agreement

Again, there are substantial differences between the varieties involved. The data were analysed with a linear mixed effect model with the judging time as dependent variable, random intercepts for participants and items, and 'Group', 'Pronoun', 'Antecedent (masc/neut)' as well as all two- and three-way interactions as predictors. As this analysis yielded several significant two-way and three-way interactions, we conducted additional separate analyses in the following. In a first step, we focused on potential overall effects of Group on the decision times. As non-native speakers plausibly will show slower reaction times due to their status as non-native speakers, this group was excluded from this analysis. Linear mixed effect models with Group (Netherlandic Dutch, Belgian Dutch, German) as predictor revealed a marginally significant difference in overall decision time between Netherlandic and Belgian Dutch $(\mathrm{z}=1.92, \mathrm{p}=.06)$, a significant difference between Netherlandic Dutch and German $(\mathrm{z}=.68, \mathrm{p}<.01)$, and no significant difference between Belgian Dutch and German $(\mathrm{z}=0.88, \mathrm{~ns})$. These differences reflect the fact that the Netherlandic participants made their decisions more slowly than the German participants, with the Belgian participants situated between these two groups. ${ }^{5}$ This may be interpreted to indicate that a system in which semantic

5 To interpret the RTs of the Belgian participants properly, it should be pointed out that these were recruited from a pool of experienced test persons, whereas the Netherlandic and German participants were novices. This may have affected RTs. Note that for the second experiment, differences between RTs obtained from Belgian and Netherlandic participants are much smaller. 
rules have more weight could lead to slower processing of agreement than a system in which syntactic rules are predominant.

In a subsequent step, we focused on effects of the two experimental factors and their interaction for subset models for each group, as done above for the offline decisions. The results are summarized in Table 3. These results reveal a heterogeneous picture, with subtle differences, but also common tendencies among the groups.

Table 3: Mixed effect modelling of reaction times (RT) from Experiment 1, in relation to 'Antecedent (masc/neut)', 'Pronoun' and their interaction, for four participant groups

\begin{tabular}{llll}
\hline & Antecedent (masc/neut) & Pronoun & Antecedent * Pronoun \\
\hline Dutch (NL) & n.s. & $\begin{array}{l}z=2.35 \\
p<.05 *\end{array}$ & n.s. \\
& & $z=1.77$ & n.s. \\
Dutch (B) & $z=4.42$ & $p=.08$ & \\
& $p<.001 * \star \star$ & n.s. & $z=2.96$ \\
L2 Dutch & n.s. & & $p<.01$ ** \\
(L1 German) & & $z=2.51$ & n.s. \\
German & $z=2.59$ & $p<.05 *$ & \\
\hline
\end{tabular}

Across the board, RTs with neuter nouns are shorter than with masculine nouns, leading to a significant effect in the Belgian Dutch and the German group. The effect is most strongly observed in Belgian Dutch, where it can be related to the fact that syntactic and semantic agreement yield conflicting outcomes for masculine mass nouns. That the effect is not found in Netherlandic Dutch is due to the strikingly slow RTs for neut_hij/er, causing an overall asymmetry between RTs for neuter and masculine pronouns. An opposite effect for Pronoun is found in German, which shows slower RTs for combinations with neuter es 'it' than with masculine pronouns, and especially for masc_het/es. Since this relates to a non-marginal acceptance of masc_het/es in comparison to neut_hij/er, it is possibly the result of semantics interfering with grammatical agreement.

The slow RTs for masc_hij/er illustrate that grammatical agreement is no longer the most expected option for L1 speakers of Dutch. The German learners, in contrast, provide the clearest evidence for a mainly grammatically dominated agreement system. In this group, a mismatch between the gender of the antecedent and the gender of the pronoun consistently led to longer reaction times, yielding a significant interaction between the two factors in this group. That such 
an effect is not visible in L1 German is due to the unexpectedly fast decision times for the neut_hij/er condition. It is possible that the ungrammaticality of this structure was so striking for the L1 German group that it led to particularly fast rather than particularly slow decision times. Whether and under which conditions such a pattern surfaces could be further investigated in future studies.

\subsection{Experiment 2: preservation of feminine gender}

Experiment 2 is geared towards testing the resilience of feminine gender. Figure 3 shows the proportions in which combinations of both masculine and feminine nouns with masculine and feminine pronouns are accepted. German is expected to have maintained a clear distinction between masculine and feminine gender, unlike Netherlandic varieties of Dutch, which have collapsed masculine and feminine gender. Such a tendency towards 'masculinisation' is also observed in Belgian Dutch production data (Geeraerts 1992), but has not reached completion there. Figure 3 confirms that the masculine-feminine distinction is still clear-cut in German, whereas it has blurred in Dutch, including German learner Dutch.

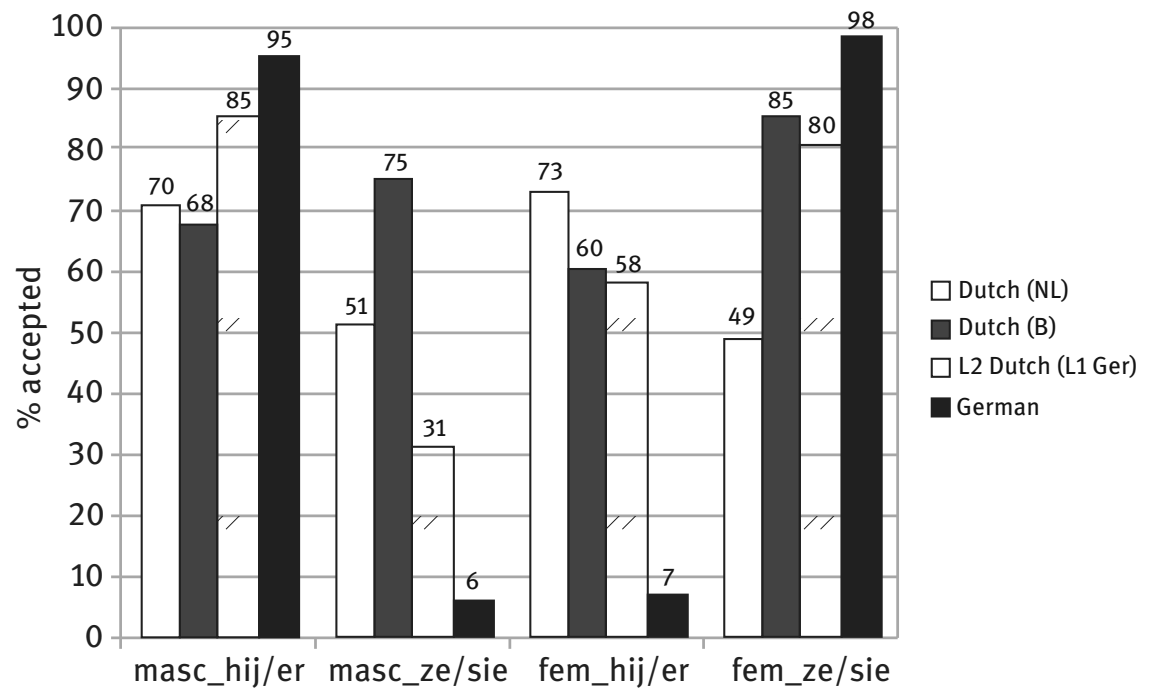

Fig. 3: Grammaticality judgements on syntactic agreement with masculine vs. feminine gender

As was done for Experiment 1, the data were analysed with generalized linear mixed effect models. A complex model involving the three-way interaction between 
'Group', 'Antecedent (masc/fem)' and 'Pronoun' did not converge. Given that as in Experiment 1, we had no hypotheses regarding a main effect of Group, we conducted subset analyses for each of the four Groups. The results are summarized in Table 4.

Table 4: Experiment 2: Mixed effect modelling of factors 'Antecedent', 'Pronoun' and their interaction, for four participant groups

\begin{tabular}{|c|c|c|c|}
\hline & Antecedent (masc/fem) & Pronoun & Antecedent * Pronoun \\
\hline Dutch (NL) & n.s. & 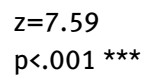 & n.s. \\
\hline Dutch (B) & n.s. & 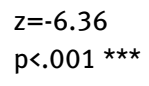 & $\begin{array}{l}z=-3.66 \\
p<.001 * \star \star\end{array}$ \\
\hline $\begin{array}{l}\text { L2 Dutch } \\
\text { (L1 German) }\end{array}$ & $\begin{array}{l}z=2.30 \\
p<.05 \text { * }\end{array}$ & 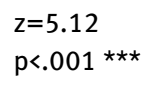 & 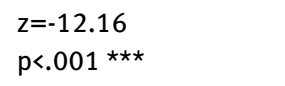 \\
\hline German & n.s. & n.s. & 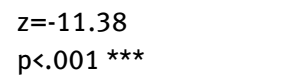 \\
\hline
\end{tabular}

These results show that the Netherlandic Dutch participants are the only ones who do not take the masculine-feminine distinction into account at all, as reflected in the fact that it is the only group in which there is no interaction between the two experimental factors. Instead, there is a main effect of Pronoun, which is due to the fact that $h i j$ 'he' is judged as acceptable in about $20 \%$ more of the cases than $z e$ 'she', irrespective of the grammatical gender of the antecedent. This confirms the process of masculinisation for Netherlandic Dutch that was mentioned above. In the three other groups, there is an interaction between the two experimental factors, due to the fact that the pronouns hij/er 'he' and $z e / s i e$ 'she' are judged differentially depending on the grammatical gender of the antecedent, thus reflecting the masculine-feminine distinction. This interaction differs in strength in the three groups, however. As expected, it is clearest in the L1 German group, where Figure 3 shows that more than 90\% of masculine pronouns are accepted with masculine nouns, and a similar proportion of feminine pronouns with feminine nouns. Use of a non-agreeing pronoun is judged ungrammatical (the scores of $<10 \%$ are comparable to those of ungrammatical fillers). The absence of a main effect of Pronoun demonstrates that both pronominal forms are accepted to similar degrees. In the Belgian speakers of Dutch, there is only weak evidence of a distinction between masculine and feminine gender. While the interaction between Pronoun and Antecedent (masc/fem) plausibly 
reflects some knowledge of grammatical gender, the preference of $z e$ 'she' over hij 'he' is more general, since it is also observed in masculine nouns (where it amounts to a mere $7 \%$ difference, which is much less than $25 \%$ for feminine nouns), and yields a reverse effect for Pronoun in comparison to Netherlandic Dutch. Finally, in the German learners of Dutch, the interaction between the factors 'Antecedent (masc/fem)' and 'Pronoun' reaches the same strength as in L1 German, suggesting that grammatical gender is transferred from the L1 to the L2, and that it is the dominant factor of influence on the judgements. In addition, however, the learners show masculinisation: they accept hij 'he' with feminine antecedents much more often (i.e. $27 \%$ more) than $z e$ 'she' with masculine antecedents, yielding a main effect of pronoun. As there are no signs of a similar tendency in the L1 German data, this is probably knowledge that these learners have acquired in the target language.

A separate analysis was run for the variable 'Frequency'. Since it may be hypothesized that the lexical gender of more frequent nouns has a higher chance to be acquired, high frequency is expected to hamper masculinisation, at least in varieties marking the masculine-feminine distinction. In general, the attested frequency effects link high frequency to resilience to change, as expected, but the effects appear relatively unsystematically and are weak. The Belgian Dutch data reveal a marginally significant interaction between the factors Antecedent (masc/fem) and Frequency ( $\mathrm{z}=1.94, \mathrm{p}=.05$ ), which is predominantly carried by the high acceptance of the fem_hij condition for less frequent nouns. In the learner group, Experiment 2 yielded a significant three-way-interaction between Frequency, Antecedent (masc/fem) and Pronoun ( $\mathrm{z}=2.80, \mathrm{p}<0.01)$, which is mainly due to the higher acceptance of hij 'he' with the less frequent feminine antecedents, and the higher acceptance of $z e$ 'she' with the more frequent feminine antecedents.

The overall picture thus is one of a continuum, in which the Netherlandic Dutch group and the German group represent two extremes, with no knowledge of grammatical gender in one group, and no baseline preference for one of the two pronouns in the other group. The German learners of Dutch show an intermediate position, with a moderate degree of masculinisation, as does the Belgian Dutch group, which reveals an overall preference for feminine $z e$ 'she'. To our knowledge, this overall preference for $z e$ 'she' has not been found in other studies, and contrasts rather sharply with spontaneous production data. For masculine inanimates in the Belgian part of the Spoken Dutch Corpus, De Vos (2014: 55) calculates figures of $62 \%$ masculine vs. $2 \%$ feminine pronouns; for feminine nouns figures are found of $43 \%$ feminine and $6 \%$ masculine pronouns, respectively. Rather than the preference for $z e$ 'she' oberved in our Experiment 2, then, spontaneous production data show a fairly resilient masculine-feminine 
distinction, and most deviations from grammatical gender in spontaneous speech can be analysed as semantically motivated instances of het 'it'. Still, there appears to be some asymmetry in the production data, too, in that feminine gender triggers more semantically motivated het 'it', and some masculinisation is observed ( $6 \%$ of pronominal references to feminines are with masculine pronouns).

When comparing the overall acceptance rates from Experiment 2 to previous production studies, it becomes evident that in the Netherlandic data, too, a remarkable tolerance is observed towards combinations that are rare in spontaneous production, in particular combinations with ze 'she'. Thus, Audring (2009a: 96) finds feminine pronouns only for animate reference in her Netherlandic data, in contrast to their acceptance ratio of around 50\% (51\% for masculines and $49 \%$ for feminines) in Figure 3. While such a high acceptance may partly result from exposure to alternative variants (for instance because Belgian Dutch shows masculinisation, too, and Netherlandic speakers may be familiar with three-gender varieties of Dutch), the remarkable discrepancies with usage data also point towards a general uncertainty regarding gender agreement. This uncertainty may be more visible in the current paradigm, where participants cannot avoid judgements for forms of which they feel unsure, whereas in spontaneous production, gender-marked pronouns are indeed avoided (Audring/ Booij 2009). In combination with the so-called acquiescence-bias (or 'yes'-bias effect), this may explain a substantial proportion of yes-answers (cf. Sabourin et al. 2006: 17). A comparison with Experiment 1, however, allows the generalisation that the distinction between common (i.e., masculine and feminine de-words) and neuter nouns (het-words) is much more solid in Dutch than distinctions within common gender.

With respect to RTs, the expectation that ungrammaticality correlates with longer RTs (Hopp 2007: 238) often does not allow strong predictions, in that differences in acceptability between the conditions in Experiment 2 are very subtle for most varieties involved. In addition, even in L1-German, which is the only variety with clearly ungrammatical combinations in the experiment, RT differences remain limited. The descriptive results are presented in Figure 4.

A complex statistical model involving all factors yielded several two-way as well as a marginally significant three-way interaction. As for Experiment 1, we thus proceeded to subset analyses. In a first step, we tested for a main effect of Group on Judgement times, again excluding the non-native speakers. These analyses revealed no significant difference between the Netherlandic and Belgian Dutch speakers, a marginal difference between the data for Belgian Dutch and for German ( $\mathrm{z}=-1.91, \mathrm{p}=.06)$, and a significant difference between Netherlandic Dutch and German $(z=3.34, p<.01)$. These results correlate clearly with the resilience of 
the three-gender system. The consistently faster RTs for German seem to confirm that a system with a strong propensity towards grammatical agreement allows for faster processing of agreement relations.

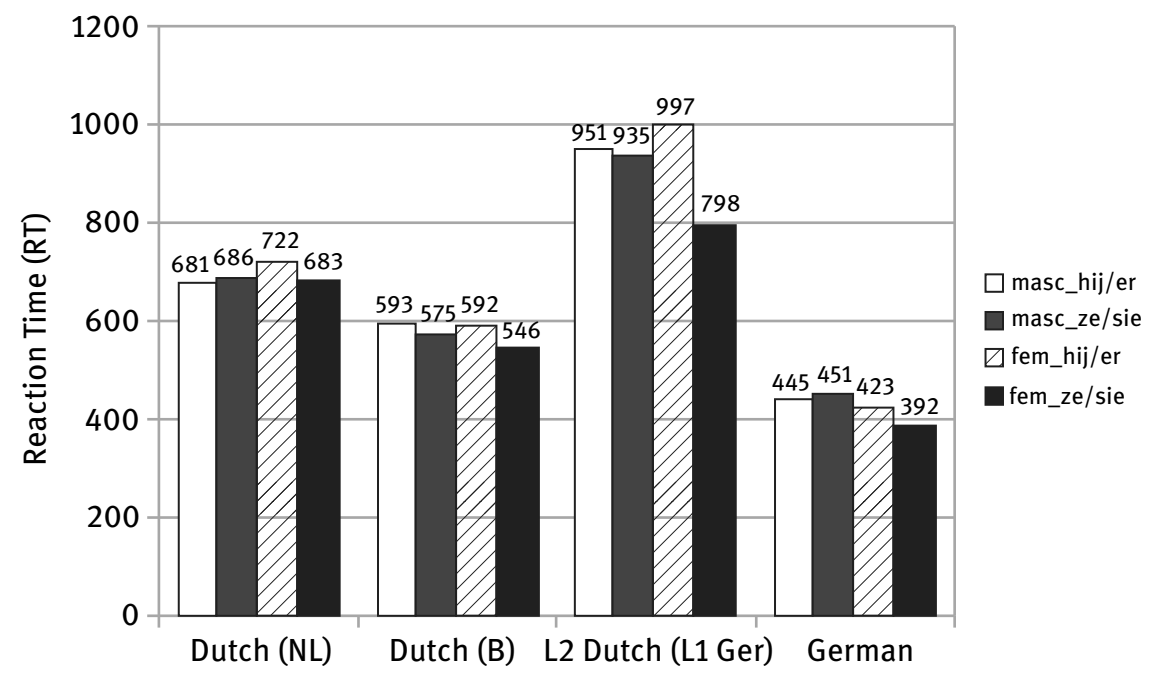

Fig. 4: Reaction times (milliseconds) on syntactic agreement with masculine vs. feminine gender

Turning to potential effects of the factors on RTs in the four groups, there were no significant effects in any of the three L1 groups. While in the two Dutch-speaking groups, this may be taken as a reflection of rather subtle differences, it probably reflects particularly striking and categorical differences for the L1 speakers of German, which led to the grammatical sentences being quickly recognized as grammatical, and the ungrammatical ones as ungrammatical. As for the learners, there was a significant main effect of Pronoun $(\mathrm{z}=2.83, \mathrm{p}<.01)$, and a significant interaction between Pronoun and Antecedent (masc/fem) $(\mathrm{z}=2.48, \mathrm{p}<.05)$ (see also Urbanek et al. 2017). Both effects are probably carried by the particularly fast reaction times for the fem_ze/sie condition. While one should be weary of premature generalisations, this may result from feminine $z e / s i e$ 'she' not being available for semantic agreement in the inanimate domain, and the fem_ze/sie-condition thus being the one in which the least competition between syntactic and semantic agreement is observed. 


\section{Conclusions}

At the outset of this article, three hypotheses were formulated regarding the psycholinguistic status of grammatical gender in the varieties included in the investigation. First, syntactic agreement was expected to be the dominant agreement mode in German pronouns, and be more stable in Belgian Dutch than in Dutch from the Netherlands. German learners of Dutch are expected to rely on lexical gender, which means use syntactic agreement, more than on semantics. The expectation that German speakers and German learners of Dutch predominantly rely on syntactic agreement was borne out, whereas differences between the resilience of syntactic agreement in Netherlandic and Belgian Dutch were more subtle than could have been expected on the basis of the literature on spontaneous production. Second, German has a stable three-gender system, whereas feminine gender is vulnerable in Dutch: Netherlandic Dutch yields similar results for masculine and feminine nouns, which are thus collapsed into the category of common gender; Belgian Dutch maintains the distinction but hardly in a robust fashion. This is not to say that there are no differences between Belgian and Netherlandic Dutch, however, in particular with respect to the degree with which hij 'he' vs. $z e$ 'she' is accepted by default for common gender antecedents. Third, semantic agreement is more strongly observed in Netherlandic Dutch than in Belgian Dutch although here too, the difference is far from spectacular. German shows a non-negligible amount of semantic agreement as well, and in particular allows combinations of lowly individuated non-neuter nouns and neuter pronouns.

With respect to the 'entrenchment accounts' of resemanticisation (De Vogelaer/ De Sutter 2011; De Vos/De Vogelaer 2011; Kraaikamp 2017), our experiments show that the rise of semantic agreement in Dutch relates to an increased uncertainty with respect to grammatical gender, yielding highly mixed answers for several conditions in our experiments, and high RTs across the board. Our results are complementary to studies on usage documenting highly variable pronominal gender in Dutch and slow acquisition processes, and more directly link such findings to linguistic cognition. They support a scenario assuming a causal link between linguistic uncertainty and change, in that semantic agreement can be considered a default option that is becoming more important as the knowledge of the grammatical gender system is affected by processes of deflection rendering invisible the distinction between masculine and feminine gender. This seems to be corroborated by a number of frequency effects in the data, which all link high frequency to resilience to change, as expected in entrenchment accounts. However, the nouns in the investigation yield relatively unsystematic and weak effects, which may be due to the fact that they only cover a limited frequency range. 
In general, the overall faster RTs in L1 German may be interpreted as an indication that an agreement system with a strong propensity towards syntactic agreement allows for faster processing of agreement relations than systems in which semantic agreement plays a larger role. This would be consistent with the alleged function of grammatical gender as a device helping to keep track of reference across discourse (see Contini-Morava/Kilarski 2013 for discussion). It is unclear, however, to what extent such a generalisation would extend beyond the Germanic varieties included in the present investigation and hold for other languages where syntactic and semantic agreement potentially conflict, which is, typologically speaking, common in gender systems (cf. Corbett 2013). In the varieties of Dutch discussed here, processes of deflection and the covert nature of gender assignment have rendered grammatical gender vulnerable, but have not obliterated it. It remains an open question what would be the impact if semantic agreement assumed an even more prominent status than it presently has in Dutch. A language such as English, for instance, has by and large lost its grammatical gender in favour of semantically driven pronominal reference. Mills (1986: 91f.) shows that children acquire such a semantic system of pronominalisation more slowly than a German-style syntactic agreement. This may indicate that semantic agreement can indeed be cognitively challenging. It remains to be tested, however, whether this slow acquisition corresponds to higher RTs in experiments like the ones carried out in this study.

\section{References}

Anderson, John A.E./Mak, Lorinda/Keyvani Chahi, Aram/Bialystok, Ellen (2017): The language and social background questionnaire: Assessing degree of bilingualism in a diverse population. In: Behavioural Research Methods, 50, 1. 250-263.

Audring, Jenny (2006): Pronominal gender in spoken Dutch. In: Journal of Germanic Linguistics $18,2.85-116$.

Audring, Jenny (2009a): Reinventing pronoun gender. Utrecht: LOT.

Audring, Jenny (2009b): Gender assignment and gender agreement: Evidence from pronominal gender languages. In: Morphology 18, 2. 93-116.

Audring, Jenny/Booij, Geert (2009): Genus als probleemcategorie. In: Taal en Tongval 61, 1. 13-37. Blom, Elma/Polišenská, Daniela/Weerman, Fred (2008): Articles, adjectives and age of onset: The acquisition of Dutch grammatical gender. In: Second Language Research 24, 3. 297-332.

Contini-Morava, Ellen/Kilarski, Marcin (2013): Functions of nominal classification. In: Language Sciences 40. 263-299.

Corbett, Greville (1991): Gender. Cambridge: Cambridge University Press. 
Corbett, Greville (2013): Systems of gender assignment. In: Dryer, Matthew/Haspelmath, Martin (eds.): The world atlas of language structures online. Leipzig: Max Planck Institute for Evolutionary Anthropology. http://wals.info/chapter/32 (last accessed: 14-12-2018).

Cornips, Leonie/Hulk, Aafke (2006): External and internal factors in bilingual and bidialectal language development: Grammatical gender of the Dutch definite determiner. In: Lefebvre, Claire/White, Lydia/Jourdan, Christine (eds.): L2 acquisition and Creole genesis:

Dialogues. (= Language Acquisition and Language Disorders 42). Amsterdam: Benjamins. 355-377.

De Houwer, Annick (1987): Nouns and their companions - or how a three-year-old handles the Dutch gender system. In: Belgian Journal of Linguistics 2, 1. 55-73.

De Vogelaer, Gunther (2010): (Not) acquiring grammatical gender in two varieties of Dutch. In: Geeraerts, Dirk/Kristiansen, Gitte/Peirsman, Yves (eds.): Advances in cognitive sociolinguistics. (= Cognitive Linguistics Research 45). Berlin/New York: De Gruyter. 167-190.

De Vogelaer, Gunther (2012): Frequency, conservative gender systems, and the languagelearning child: Changing systems of pronominal reference in Dutch. In: Gries, Stefan Th./ Divjak, Dagmar (eds.): Frequency effects in language. Vol. 1: Frequency effects in language learning and processing. (= Trends in Linguistics 244) Berlin/Boston: De Gruyter. 109-144.

De Vogelaer, Gunther/De Sutter, Gert (2011): The geography of gender change: Pronominal and adnominal gender in Flemish dialects of Dutch. In: Language Sciences 33, 1. 192-205.

De Vos, Lien (2013): On variation in gender agreement: The neutralization of pronominal gender in Dutch. In: Giacalone Ramat, Anna/Mauri, Caterina/Molinelli, Piera (eds.): Synchrony and diachrony: A dynamic interface. (= Studies in Language Companion Series 133). Amsterdam: Benjamins. 237-260

De Vos, Lien (2014): Pronominal resemanticization in Dutch: A salience-driven redistribution of gender-marked pronouns. University dissertation. Liège.

De Vos, Lien/De Vogelaer, Gunther (2011): Dutch gender and the locus of morphological regularization. In: Folia Linguistica 45, 2. 245-281.

Duden (2015): Deutsches Universalwörterbuch. Das umfassende Bedeutungswörterbuch der deutschen Gegenwartssprache. 8th revised and expanded edition. Berlin: Duden.

Fernández-Ordóñez, Inés (2009): The development of mass/count distinctions in Indo-European varieties. In: Bubenik, Vit/Hewson, John/Rose, Sarah (eds.): Grammatical changes in Indo-European languages: Papers presented at the Workshop on Indo-European Linguistics at the XVIIIth International Conference on Historical Linguistics, Montreal, 2007. (= Current Issues in Linguistic Theory 305). Amsterdam: Benjamins. 55-68.

Geeraerts, Dirk (1992): Pronominale masculiniseringsparameters in Vlaanderen. In: Bennis, Hans/de Vries, Jan (eds.): De binnenbouw van het Nederlands: Een bundel artikelen voor Piet Paardekooper. Dordrecht: ICG Publications. 73-84.

Grote Van Dale (2015) = Van Dale Redactie: Groot woordenboek van de Nederlandse taal. 15th edition. Utrecht/Antwerpen: Van Dale Uitgevers.

Hopp, Holger (2007): Ultimate attainment at the interfaces in second language acquisition: Grammar and processing. (= Groningen Dissertations in Linguistics 65). Groningen: Rijksuniversiteit Groningen.

Hoppenbrouwers, Cor (1983): Genus in een Brabants regiolect. In: TABU. Bulletin voor Nederlandse Taalkunde 13. 1-25. 
Jobin, Bettina (2011): Semantically driven change in German(ic) gender morphology. In: Folia Linguistica 45, 2. 317-353.

Keuleers, Emmanuel/Brysbaert, Marc/New, Boris (2010): SUBTLEX-NL: A new frequency measure for Dutch words based on film subtitles. In: Behavior Research Methods 42, 3. 643-650.

Klom, Jan/De Vogelaer, Gunther (2017): Semantic agreement competing with syntactic agreement: The case of Dutch pronouns. In: Leuven Contributions in Linguistics and Philology 101. 123-149.

Köpcke, Klaus-Michael/Zubin, David (1983): Die kognitive Organisation der Genuszuweisung zu den einsilbigen Nomen der deutschen Gegenwartssprache. In: Zeitschrift für Germanistische Linguistik 11, 2.166-182.

Kraaikamp, Margot (2017): Semantic versus lexical gender. Synchronic and diachronic variation in Germanic gender agreement. Utrecht: LOT.

Lemhöfer, Kristin/Schriefers, Herbert/Hanique, Iris (2010): Native language effects in learning second-language grammatical gender: A training study. In: Acta Psychologica 135, 2. 150-158.

Loerts, Hanneke (2012): Uncommon gender. Eyes and brains, native and second language learners \& grammatical gender. Groningen: Rijksuniversiteit Groningen.

Luraghi, Silvia (2011): The origin of the Proto-Indo-European gender system: Typological considerations. In: Folia Linguistica 45, 2. 435-463.

Matasovič, Ranko (2004): Gender in Indo-European. Heidelberg: Winter.

Mills, Anne E. (1986): The acquisition of gender. A study of English and German. (= Springer Series in Language and Communication 20). Berlin: Springer.

Sabourin, Laura/Stowe, Laurie/De Haan, Ger (2006): Transfer effects in learning a second language grammatical gender system. In: Second Language Research 221, 1. 1-29.

Sasse, Hans-Jürgen (1993): Syntactic categories and subcategories. In: Jacobs, Joachim/ Stechow, Arnim von/Sternefeld, Wolfgang/Vennemann, Theo (eds.): Syntax. Ein internationales Handbuch zeitgenössischer Forschung/An international handbook of contemporary research. (= Handbücher zur Sprach- und Kommunikationswissenschaft/ Handbooks of Linguistics and Communication Science 9.1). Berlin/Boston: De Gruyter. 646-686.

Schneider, Walter/Eschman, Amy/Zuccolotto, Anthony (2012): E-Prime reference guide. Pittsburgh: Psychology Software Tools Inc.

Schwink, Frederick W. (2004): The third gender: Studies in the origin and history of Germanic grammatical gender. Heidelberg: Winter.

Siemund, Peter (2008): Pronominal gender in English: A study of English varieties from a cross-linguistic perspective. New York: Routledge.

Szagun, Gisela/Stumper, Barbara/Sondag, Nina/Franik, Melanie (2007): The acquisition of gender marking by young German speaking children: Evidence for learning guided by phonological regularities. In: Journal of Child Language 34, 3. 445-471.

Tremblay, Annie (2005): Theoretical and methodological perspectives on the use of grammaticality judgement tasks in linguistic theory. In: Second Language Studies 24, 1. 129-167.

Urbanek, Lukas/Poarch, Greg/Schimke, Sarah/Fanta, Johanna/De Vogelaer, Gunther (2017): 'Anders, of toch niet?' Het Nederlandse pronominale genus door de bril van Duitse NVT-leerders. In: Dutch Journal of Applied Linguistics (DuJAL) 6, 2. 147-173.

Van der Velde, Marlies (2003): Déterminants et pronoms en néerlandais et en français: Syntaxe et acquisition. Paris: Université Paris VIII. 
Van Emmerik, Joanne/van Hout, Roeland/van de Craats, Ineke/Klatter-Folmer, Jetske (2005): 'Het' gaat niet vanzelf. De verwerving van het genus door dove volwassenen en horende tweedetaalleerders. In: Taal en Tongval 61, 1. 188-226.

Van Ginneken, Jacobus (1934-1935): De geschiedenis der drie geslachten in Nederland. In: Onze Taaltuin 3, 2. 33-42.

Van Ginneken, Jacobus (1936-1937): Het onbepaald lidwoord en het geslacht. In: Onze Taaltuin 5, 12. 353-356.

Wurzel, Wolfgang U. (1986): Die wiederholte Klassifikation von Substantiven. Zur Entstehung von Deklinationsklassen. In: Zeitschrift für Phonetik, Sprachwissenschaft und Kommunikationsforschung 39, 1. 76-96. 
